\title{
¿DOBLES O ESPÍRITUS? \\ LAS TEORÍAS DEL DESDOBLAMIENTO FRENTE AL ESPIRITISMO EN LA ESPAÑA DE PRINCIPIOS DEL SIGLO XX
}

\author{
Andrea Graus \\ Centre d'Història de la Ciència (CEHIC), Universitat Autònoma de Barcelona \\ andrea.graus@gmail.com
}

Recibido: 7 febrero 2013; Aceptado: 27 mayo de 2013.

Cómo citar este artículo/Citation: Graus, Andrea (2014), “¿Dobles o espíritus? Las teorías del desdoblamiento frente al espiritismo en la España de principios del siglo XX", Asclepio 66 (1): p035, doi: http://dx.doi.org/10.3989/asclepio.2014.09

RESUMEN: El presente artículo aborda la relación entre las teorías del desdoblamiento y el espiritismo en España. Se exponen dos casos acontecidos a principios del siglo XX. El primero describe el desdoblamiento de la personalidad que el médico Víctor Melcior atribuyó a la médium Teresa Esquius. El segundo trata la polémica, entre el astrónomo Josep Comas y el espiritista Jacint Fornaguera, respecto al desdoblamiento corporal en la médium Carmen Domínguez. Se argumenta que esta clase de debates favorecieron el estudio científico de la mediumnidad.

PALABRAS CLAVE: Desdoblamiento; Espiritismo; Mediumnidad; Metapsíquica; Doble Personalidad.

\section{DOUBLES OR SPIRITS?}

DISSOCIATION THEORIES AGAINST SPIRITISM IN SPAIN AT THE BEGINNINGS OF THE $20^{\text {TH }}$ CENTURY

ABSTRACT: This paper discusses the relation between dissociation theories and spiritism in Spain. It shows two cases that took place at the beginnings of the 20th Century. The first describes the mental dissociation that the physician Víctor Melcior attributed to the medium Teresa Esquius. The second shows the polemic, between the astronomer Josep Comas and the spiritist Jacint Fornaguera, in regard to the bodily dissociation in the medium Carmen Domínguez. It is argued that these kind of debates favoured the scientific study of mediumship.

KEY WORDS: Dissociation; Spiritualism; Mediumship; Psychical Research; Secondary Self.

Copyright: (C) 2014 CSIC. Este es un artículo de acceso abierto distribuido bajo los términos de la licencia Creative Commons Attribution-Non Commercial (by-nc) Spain 3.0. 


\section{INTRODUCCIÓN}

A lo largo del siglo XIX despertó el interés por los fenómenos del desdoblamiento de la personalidad, los cuales fueron relacionados con los campos del magnetismo y el espiritismo (Véase, por ejemplo: Plas, 2012; Wolffram, 2012; Méheust, 1999; Crabtree, 1993; Shamdasani, 1993, 1994; Oppenheim, 1985). Como mostró Ellenberger (1976) en su clásico The discovery of the unconscious, el auge del espiritismo contribuyó al desarrollo de las distintas nociones sobre el inconsciente, como la idea del subconsciente de Pierre Janet. Al teorizar sobre la disociación psicológica y la formación de segundas personalidades, Frederic W. H. Myers, Edmund Gurney, Théodore Flournoy, Alfred Binet o Pierre Janet se basaron en casos propios de la mediumnidad y el sonambulismo natural (Sommer, 2011; Alvarado, 2002, 2010; Léblanc, 2001; Shamdasani, 1994; Ellenberger, 1976). Como argumentaré en este artículo, en España la definición de Janet del desdoblamiento de la personalidad, en relación al espiritismo, fue la más difundida. Se encargaron de promoverla médicos y psiquiatras interesados por los fenómenos mediúmnicos, como Víctor Melcior y Farré o Antonio Gota Casas (Gota, 1909a, 1909b; Melcior, 1904, 1900).

Aparte del desdoblamiento en sentido psicológico, investigadores de los fenómenos paranormales como Albert de Rochas d'Aiglun defendieron la existencia de un desdoblamiento físico o corporal. En su grado máximo, el individuo fluídico o doble se desprendía del cuerpo del médium o, en su caso, del sujeto hipnotizado (Rochas, 1897). La exteriorización del doble permitía, según Rochas (1897), explicar fenómenos físicos propios del espiritismo, como la levitación o los aportes, sin la intervención de los espíritus. Así lo defendieron Hector Durville o Hyppolite Baraduc, investigadores en el campo del magnetismo, en el Congreso de Psicología de París de 1900. En este, los temas relacionados con los fenómenos espiríticos tuvieron una hostil acogida debido a la oposición de algunos asistentes, como el neurólogo alemán Oskar Vogt (Brower, 2010; Plas, 2000). En España, aunque las teorías de Rochas no tuvieron una gran acogida, fueron defendidas por médicos como Abdón Sánchez Herrero (1852-1904), amplio conocedor de los fenómenos del hipnotismo trascendental.

La historiografía sobre el hipnotismo y la metapsíquica ${ }^{1}$ ha destacado la importancia de las teorías del desdoblamiento en las primeras sociedades dedicadas al estudio de los fenómenos mediúmnicos, como la Society for Psychical Research o la Société Psychologique Physiologique (Lachapelle, 2011; Wolffram, 2009a; Edelman, 2006a; Owen, 2004; Méheust, 1999). En el contexto español se hallan trabajos notables sobre el espiritismo (González de Pablo, 2006a; Abend,
2004; Horta 2001, 2004), el magnetismo e hipnotismo (González de Pablo, 2006b; Montiel \& González de Pablo, 2003) y la metapsíquica (Mülberger \& Balltondre, 2012, 2013; Mülberger, 2008; Roca, 1986). Sin embargo, la influencia de las teorías del desdoblamiento, en relación al estudio científico de la mediumnidad, sigue inexplorada. El propósito del presente artículo es profundizar en este tema.

Según argumentaré, el desdoblamiento, ya fuera en sentido físico o psicológico, cuestionaba la hipótesis espiritista. El médium dejaba de ser considerado como un mediador entre los vivos y los desencarnados. Sus fenómenos se creían producto de fuerzas inconscientes y desconocidas. Para comprender la importancia de esta cuestión se relatarán dos controversias, hasta ahora no estudiadas, en torno a la disociación y la mediumnidad. Ambas polémicas representan dos ejemplos notables del impacto de las teorías del desdoblamiento en España a principios del s. XX. Como se verá, dichas teorías fueron presentadas por algunos médicos como la explicación racional de la posesión espiritual. Esta actitud, sostenida por psicólogos como Pierre Janet o Julian Ochorowicz, y generó importantes debates en la línea de los que se van a exponer (Véase, por ejemplo: Brower, 2010; Plas 2000). Asimismo, los espiritistas españoles tampoco fueron ajenos a esta clase discusiones, como mostraré en este artículo.

El primer caso que expondré se refiere a la médium Teresa Esquius, a quien el médico Víctor Melcior y Farré (1860-1929) diagnosticó un desdoblamiento de la personalidad. Este desdoblamiento fue sanado mediante terapia hipnótica por parte de Melcior. El segundo caso trata de la polémica, entre el astrónomo Josep Comas y Solà (1868-1937) y el espiritista Jacint Fornaguera, respecto al desdoblamiento corporal en la médium Carmen Domínguez. En ambos casos, muy polémicos entre los espiritistas, se observarán las implicaciones que supone refutar la hipótesis espírita y entender la mediumnidad como producto de un desdoblamiento. Finalmente, argumentaré que este debate contribuyó a fomentar el estudio científico de la mediumnidad.

\section{LA «VERDADERA» MEDIUMNIDAD}

El desdoblamiento de la personalidad, así como otros fenómenos relacionados con el inconsciente, como la autosugestión, fueron percibidos por muchos espiritistas como una amenaza. Quintín López Gómez (1864-1934), espiritista reconocido y amigo de Melcior, defendió la necesidad de distinguir los fenómenos del desdoblamiento y la autosugestión de la "verdadera» mediumnidad, o sea, aquella en la que intervenían los espíritus (López, s.d. 1919?). Esta cuestión fue debatida en el Segundo Congreso Espiri- 
tista y Espiritualista, celebrado en París en 1900. Entre las circulares que publicó la comisión del congreso en relación a los temas que se tratarían en el encuentro, se planteó que los hechos del desdoblamiento obligaban a los espiritistas a reemprender el estudio de la mediumnidad tendiendo en cuenta factores humanos como la memoria o la autosugestión. De este modo, se pretendía establecer «la diferencia entre el automatismo y la mediumnidad» para "distinguir los verdaderos fenómenos espiritistas de aquellos que no tienen de tales más que la apariencia» (Comisión de organización de la sección espiritista, 1900, p. 85).

Para los espiritistas, probar la existencia de la «verdadera» mediumnidad era necesario para diferenciar los médiums de los sonámbulos, las teorías espiritistas de las animistas, los fenómenos espiríticos de los del hipnotismo trascendental (Méheust, 1999; Wolffram, 2012; Edelman, 2006a; González de Pablo, 2003; Bensaude-Vincent \& Blondel, 2002;). El médico y espiritista Eugenio García Gonzalo intentó calmar los ánimos de sus correligionarios afirmando que aquellos científicos interesados por el espiritismo, como Zöllner, terminarían por clasificar los fenómenos mediúmnicos y desvelar «cuáles son debidos exclusivamente a nuestro organismo, cuáles a nuestra fuerza psíquica, y cuáles a la intervención espiritual ultraterrestre» (García, 1897, p. 298).

Con el mismo propósito de probar la existencia de la "verdadera» mediumnidad obró el médium Segundo Oliver. Alrededor de 1900 convocó un premio, que pasó de 3.000 a 20.000 pesetas, para quien demostrara que uno de los fenómenos que producía, el retrato de personas muertas desconocidas, podía explicarse mediante una teoría que no fuera el espiritismo de Kardec (Esteva, 1901; Oliver, 1901). Entre las muchas teorías recibidas, las cuales Oliver rechazó, se hallaba la del desdoblamiento de la personalidad (Oliver, 1901).

Para médicos como Víctor Melcior (1904) o Antonio Gota (1909a, 1909b), las teorías relacionadas con el desdoblamiento eran las mejor aceptadas por miembros de la comunidad científica como Enrico Morselli (1908) o Charles Richet (1923). En palabras del astrónomo Josep Comas: "Todos los autores que han estudiado seriamente el asunto [del espiritismo] sin prejuicios están conformes en que tales fenómenos podrían explicarse en principio por un desdoblamiento del médium» (Comas, 1908, p. 78).

Como argumenta Edelman (2006b), el desdoblamiento de la personalidad no solo amenazaba la «verdadera» mediumnidad, sino que representaba una lacra para los médiums. Las teorías de Janet (1889) sobre la desagregación psicológica, promovidas por Melcior, partían de la concepción del médium como un ser enfermo y desequilibrado. Junto al fraude, la patologización fue el mayor escollo que hallaron los médiums para su consideración. En España, Estrany los trató de histéricos y Tolosa Latour tachó a Home, el famoso médium escocés, de neurósico (Tolosa, 1884; Estrany, 1908). Sin embargo, no todos se conformaron con estas etiquetas. Este fue el caso del médium Jacint Fornaguera, quien polemizó con Comas respecto a la teoría sobre el desdoblamiento corporal, como veremos más adelante.

\section{EL DESDOBLAMIENTO DE LA PERSONALIDAD: UNA MÉDIUM BAJO TERAPIA}

Para ilustrar la teoría del desdoblamiento de la personalidad, aplicada a la mediumnidad, expondré el caso, aún no tratado por ningún historiador, de la joven Teresa Esquius. Esta joven médium de Terrassa fue supuestamente sanada, alrededor de 1900, por Víctor Melcior, un médico leridano afincado en Barcelona.

Melcior estaba vinculado al círculo espiritista de Quintín López, colaborador de la Revista de Estudios Psicológicos. Desde este círculo se creó, en 1895, la Clínica Hidro-Magnética, un consultorio médico de caridad. Melcior fue su fundador junto al médico José Cembrano. Durante diez años, ambos asistieron desinteresadamente a enfermos entre dos y tres días a la semana. La curación mediante el magnetismo y la hipnosis no solo fue presencial sino también por correspondencia, a nivel peninsular y continental, mediante el envío de libritos de papel magnetizado (Melcior, 1895; Anónimo, 1895).

Amplio conocedor del hipnotismo y el espiritismo, Melcior estaba interesado por los trastornos de la personalidad y su relación con el inconsciente. En su libro Los estados subconscientes y las aberraciones de la personalidad (1904) narra el desdoblamiento de la joven Teresa Esquius.

Teresa, nacida en Terrassa en 1876, de constitución débil, sufría crisis histéricas desde los trece años a raíz de una discusión con Dolores, una compañera de la fábrica donde trabajaba. Movido por la superstición, su padre consultó con tarotistas y curanderos, los cuales le dijeron que Teresa era víctima del mal de ojo. Ante el estado de salud de su hija amenazó a Dolores con matarla a ella y a su marido si no le quitaba el mal en tres días. Pasado este tiempo los síntomas desaparecieron, pero se presentaron una nueva serie de fenómenos más extraños todavía: los muebles levitaban alrededor de Teresa, se oían ruidos o crujidos y aparecían dibujos de cruces y objetos cotidianos grabados en las paredes (Melcior, 1904).

Los fenómenos preocuparon a las autoridades locales y en Terrassa empezó a correr el rumor de que Teresa estaba embrujada. Tras consultar el padre con el doctor Cadevall, director del Real Colegio Tarrasen- 
se, se concluyó que los fenómenos los producía Teresa inconscientemente. Después de que ningún tratamiento médico diera resultado, Cadevall aconsejó a la familia probar con la terapia hipnótica, para la cual acudieron a Melcior, quien rápidamente observó el desdoblamiento del yo:

Llevaron a Teresa a mi consulta, la hipnoticé desde la primera sesión, y a poco se demostró en ella una especie de convivencia entre dos seres, cuyo total formaba la personalidad de la enferma.

De manera que hallándose Teresa durmiendo con sueño sonambúlico, respondía a las preguntas que se le hacían no como Teresa en sí, es decir, no como la sujeto que en estado de vigilia era designada con dicho nombre, sino con el nombre de Teresina. Este diminutivo lo aplicaba a la personalidad subconsciente, y también a su cuerpo. (Melcior, 1904, p. 306).

Teresa estaba convencida de que Teresina era un espíritu que se posesionaba de ella para producir los fenómenos. Según Melcior, confundir estos hechos con comunicaciones de ultratumba era fácil, ya que durante el trance los médiums solían hablar de ellos mismos en tercera persona: "de ahí que, muchas personas crédulas, den como auténtica comunicación de espíritus del espacio, lo que en resumen de cuentas no es más que una conversación inter-vivos» (Melcior, 1904, p. 324).

Aunque Melcior admitía sentirse seducido por algunos puntos relacionados con la doctrina espiritista, como la reencarnación, consideraba que la explicación espírita a los cambios de personalidad «estaba desposeída de fundamento científico» y era "soberanamente ridícula» (Melcior, 1904, p. 262). A través de la sugestión en estado hipnótico destruyó la personalidad de Teresina repitiéndole a Teresa la siguiente consigna: «Cada vez que te hipnotizo, Teresina va perdiendo fuerzas. Esta operación es para ella lo mismo que para ti sería una sangría» (Melcior, 1904, p. 309). De este modo, convenció a Teresa de que no prestara su fuerza psíquica a Teresina, tras lo cual los fenómenos desaparecieron en pocas semanas. Para Melcior, quedaba probado que el caso de mediumnidad de Teresa no era consecuencia de ningún espíritu y que Teresina era producto de su inconsciente.

El fenómeno del desdoblamiento de la personalidad ya había sido observado por los magnetizadores; pero el desdoblamiento en sentido psicopatológico fue teorizado por Pierre Janet. Entre otros casos, Janet (1889) se basó en el de Lucie, una de sus pacientes histéricas que presentaba una segunda personalidad, Adrienne, con quien Janet lograba comunicarse mediante la escritura automática (Bacopoulos-Viau, 2012; Léblanc, 2001; Crabtree, 1993a;). Esta visión psicopatológica del desdoblamiento, muy extendida en el contexto francés, era contraria a la que defendió Myers en el contexto inglés. Para Myers (1903), las segundas personalidades podían ser superiores e incluso más creativas (Shamdasani, 1993). La terapia consistiría en integrar ambas personalidades en vez de eliminar la subconsciente, tal y como proponían Janet (1889) y Melcior (1904). Dada la importancia que tuvo para Melcior la teoría de Janet sobre el desdoblamiento de la personalidad, aplicada a la mediumnidad, se relatarán los puntos más importantes para después ver cómo Melcior los relacionó con el caso de Teresa.

Janet (1889) opinaba que, cuando el médium entraba en trance su yo se disgregaba y aparecía una personalidad subconsciente que lo dominaba. En este sentido, creía que la autosugestión era el mecanismo del desdoblamiento y que la formación de segundas personalidades era el punto esencial del espiritismo. Los medios que estas personalidades emplearan para manifestarse -raps, escritura automática etc.- le parecían secundarios.

La expresión que para Janet mejor describía el estado de trance era la de hémisomnambulisme, acuñada por Charles Richet (1923). En este estado el médium era capaz de mantener dos existencias simultáneas, la de su personalidad conocida y la de su subconsciente. Según Janet (1889), los médiums representaban el tipo de desdoblamiento más completo, en el cual las dos personalidades se ignoraban entre ellas y se desarrollaban de forma independiente. La mediumnidad no era, según él, más que un síntoma de un estado mórbido análogo al de la histeria.

En la explicación que da Melcior (1904) del desdoblamiento de la personalidad de Teresa se observa una clara influencia de las teorías de Janet. Melcior, al igual que Janet, concebía el desdoblamiento como un estado enfermizo que solo podía afectar a individuos desequilibrados, pues dependía de una ruptura en la coordinación física y psicológica de la persona. Para Melcior (1904), Teresa no solo padecía una «miseria fisiológica» debida a sus malas condiciones de vida, derivadas del hecho de pertenecer a la clase obrera, sino también una debilidad moral o misère psychologique, por ponerlo en términos de Janet (1889). Esa fragilidad mental era, según Melcior, la culpable de que, tras el incidente con Dolores, se constituyera en la mente de Teresa "un estado de idea fija, caracterizado por representaciones mentales de una mujer (Dolores) que la quiere mal» (Melcior, 1904, p. 312). Se observa aquí otro término usado por Janet, el de idea fija. Janet (1889) la definió como un fenómeno psicológico que se desarrolla de forma automática, natural e inconsciente, fuera de la voluntad y de la percepción personal, como una autosugestión influenciada por causas accidentales. Melcior siguió al pie de la letra esta definición, pues creyó que el incidente con Dolores fue la causa de que Teresina se 
constituyera como «una creación psicológica de la propia Teresa» (Melcior, 1904, p. 323). Es decir, que Teresa creó a Teresina mediante la autosugestión, tal y como lo había planteado Janet en el caso de Lucie (Janet, 1889).

Según Melcior, la influencia del entorno social tuvo un papel fundamental en la confusión del desdoblamiento de la personalidad de Teresa con un caso propio del espiritismo. En palabras de Melcior, Teresa se vio "sugestionada por deudos, amigos y desconocidos, empeñados en reconocerla víctima inocente de un fatal embrujamiento» (Melcior, 1904, p. 314). Al manifestarse los primeros fenómenos, el padre de Teresa consultó con un espiritista, quien le dijo que su hija se hallaba poseída por un espíritu maligno. Cuando el caso se conoció en Terrassa, este tipo de teorías triunfaron en un ambiente donde el espiritismo ganaba adeptos día a día entre la clase obrera (Horta, 2001, 2004). Prueba de ello es que a finales del siglo XIX se fundaron, solo en Terrassa, al menos cuatro centros espiritistas que estén documentados. Entre ellos, dos de renombrada importancia: el Centro Espiritista Fraternidad Humana y la Federación Espiritista del Vallés. Al mismo tiempo, Terrassa fue la sede de varias publicaciones espiritistas, de entre las cuales destaca la revista Lumen, dirigida por Quintín López.

Aunque para Melcior el caso de Teresa Esquius no formaba parte del espiritismo, sí que se incluía dentro de la mediumnidad. Para ejemplificar esta distinción merece la pena citar la opinión de Ochorowicz respecto a Eusapia Palladino y su supuesto espíritu guía, John King. En 1894, el psicólogo polaco dirigió unas sesiones con la famosa médium en Varsovia. Tras no hallar pruebas a favor de la hipótesis espiritista, la primera conclusión que extrajo fue: "John" no es para mí otra cosa que un desdoblamiento psíquico de la médium. Por consiguiente, yo soy "mediumnista" y no "espiritista" » (Cita de Ochorowicz en: Rochas, 1897, p. 130). Mediante esta clase de afirmaciones la mediumnidad dejó de ser un terreno exclusivo del espiritismo. El proyecto científico encargado de estudiar sus fenómenos, la metapsíquica, sería el abanderado de esta definición no espiritista, sino psicológica, de la mediumnidad (Sobre la metapsíquica en España ver: Mülberger \& Balltondre, 2012).

Como Ochorowicz (1887), Melcior $(1904,1900)$ opinaba que el origen de los fenómenos mediúmnicos no debía buscarse en el espiritismo, sino en los propios médiums, en su psicología. La teoría del desdoblamiento de la personalidad planteada por Janet servía para explicar la desagregación psicológica sufrida por Teresa, pero no justificaba los fenómenos físicos que producía. Como se ha comentado, estos fenómenos incluían la levitación de muebles y la aparición de grabados en las paredes. Para entender las causas que
Melcior atribuyó a estos fenómenos hay que ir un paso más allá del desdoblamiento de la personalidad y situarnos en el que, según Melcior (1904), representaba su «grado máximo»: el desdoblamiento corporal.

\section{EL DESDOBLAMIENTO CORPORAL O LA EXTERIORI- ZACIÓN DEL DOBLE}

El desdoblamiento no solo podía ser psicológico sino también físico o corporal. En este caso iba supuestamente acompañado de la irradiación, por parte del médium, de una fuerza natural, aunque desconocida, la cual provocaba fenómenos extraordinarios en distinto grado. Dicha fuerza había recibido varias designaciones, cada una con sus matices (Alvarado, 2006), aunque científicos como Melcior, Comas o Tolosa Latour tendían a equipararlas. En palabras de Comas: "Llámese a esta fuerza: fuerza psíquica [de Crookes], fuerza ódica [de Reichenbach], fuerza néurica [de Baréty], lo cierto es que en el fondo hay concordancia en admitir una emanación por parte del médium» (Comas, 1908, p. 316). Mientras Melcior $(1904,1900)$ solía utilizar la designación de "fuerza psíquica», popularizada por Crookes, a Comas (1908) le parecía más adecuada la noción de "fuerza ecténica» de Thury.

Según Melcior (1904), la irradiación de la fuerza psíquica no siempre se manifestaba con igual intensidad. En grados menores producía crujidos, movimientos de objetos, levitaciones o la aparición de luces. Por último: «en el grado superior del desdoblamiento, se desprende el cuerpo fantásmico de un vivo, trasladándose a sitios más o menos remotos, llegando a ser reconocido por la persona o personas a quienes aparece» (Melcior, 1904, pp. 316-317). Este «cuerpo fantásmico» que se desdoblaba del médium recibía muchos nombres. Para los ocultistas y los teósofos se trataba del cuerpo astral, los magnetizadores lo solían llamar cuerpo o doble fluídico, los espiritistas lo designaban como periespíritu y otros, como Durville, preferían hablar del "fantasma de un vivo» (Melcior, 1904; Durville, 1909; Kardec, 2009).

En palabras del periodista, político y escritor Santiago Valentí y Camp (1875-1934), lo que se desdobla del médium «no son personas, aunque tienen algunas apariencia de personalidad, y están en relación con las imágenes, conceptos y sentimientos del médium, de tal manera, que hasta cierto punto pueden calificarse de doble del mismo, a pesar de ser fragmentario y parcial» (Valentí \& Masseguer, 1912, p. 252). Como se verá más adelante, Comas hace una definición semejante del doble.

A este grado de desdoblamiento llegó Teresa ya que, según Melcior: «la propia enferma dice haber visto a Teresina penetrar en una habitación, mientras ella (Teresa), permanecía dormida con sueño sonam- 
búlico en una silla» (Melcior, 1904, p. 325). Solo mediante la exteriorización del doble podían explicarse, según Melcior (1904), los fenómenos físicos producidos por Teresa como los grabados o la levitación de objetos y muebles.

Según relata Melcior (1904), los grabados se hallaban en la parte alta de las paredes, por lo que Teresa hubiera necesitado de una escalera para tallarlos, y en su casa no había ninguna. Por otro lado, los fenómenos de levitación fueron presenciados por los médicos tarrasenses Pous y Cadevall. Para asegurarse de que no se trataba de un fraude, Pous colocó un duro sobre el cuerpo de Teresa, tendida en la cama, de manera que la moneda cayera con el menor movimiento. Nada más alejarse de la enferma vieron repetirse «la danza de mesas, sillas y bastón» (Melcior, 1904, p. 303), pero ni Teresa ni el duro se movieron de su sitio.

Aunque el caso de Teresa sirve para ejemplificar la teoría del desdoblamiento corporal, para profundizar en el tema se relatará la polémica entre el astrónomo Josep Comas y el espiritista Jacint Fornaguera. Ésta tuvo lugar en 1908, es decir, cuatro años después de que Melcior narrará el caso de Teresa Esquius en su libro. La discusión con Fornaguera partió de las sesiones que Comas había mantenido con la médium Carmen Domínguez, a quien se refiere como "médium $Z$ » en su recopilación de artículos titulada El espiritismo ante la ciencia (1908). La polémica entre Comas y los espiritistas, en relación a la publicación de dicho libro, ya fue tratada por Roca (1986). Sin embargo, merece la pena recordar algunas cuestiones para comprender la controversia, aún no estudiada por ningún historiador, en torno al desdoblamiento corporal en la médium Carmen.

A principios de 1907, José Cembrano comunicó a Jacint Esteva Marata, presidente de la Liga Espiritista Española, la existencia de una médium que producía asombrosos fenómenos. Entre ellos, el más controvertido: la materialización corpórea de un espíritu llamado Leonor (Esteva, 1908). La médium era Carmen Domínguez, con quien Comas ya había compartido sesiones en 1906. Carmen formaba parte del servicio de la casa de Antonio de Sard, director de los encuentros y protector de Carmen (Estrany, 1908). El médico Jeroni Estrany (1908), quien había asistido a algunas sesiones con Carmen entre 1906 y 1907, opinó que los fenómenos eran fraudulentos, pero exculpó a la médium aduciendo que el artífice era de Sard.

Como ha destacado Owen (2004), si bien la mediumnidad no era un terreno exclusivo de las mujeres fue significativo en cuanto las elevó a un posición de poder espiritual y cultural. Aunque fuera mediante "otras inteligencias» o espíritus, algunas encontraron la manera de pronunciarse respecto a temas sociales y espirituales, ganándose una autoridad difícil de con- seguir en otros círculos. En España, uno de los casos más destacados fue el de la espiritista Amalia Domingo Soler (1835-1909) (Horta, 2001, 2004).

Tras las sesiones de 1907, Comas quiso quemar las actas de los fenómenos obtenidos con Carmen para que estos no trascendieran, pues los tachó de fraudulentos (Esteva, 1908). Sin embargo, la materialización de Leonor reportó fama internacional a la médium y asombró hasta a Cesare Lombroso. En Los fenómenos de hipnotismo y espiritismo (1993) cita a Leonor como un caso excepcional de materialización de cuerpo entero², el único hasta entonces conocido junto con Katie King, el espíritu materializado por la médium Florencia Cook.

Tanto Comas (1908) como Estrany (1908) lamentaron el entusiasmo de Lombroso ante lo que consideraron un fraude. Como se verá a continuación, Comas se valió de la teoría del desdoblamiento corporal para negar la existencia de Leonor.

\section{Leonor: ¿doble o espíritu?}

A raíz de sus experiencias con Carmen, Comas clasificó los fenómenos mediúmnicos en tres grupos: los ciertos, los dudosos y los falsos. Entre los primeros incluyó pequeños fenómenos físicos, como los raps o los efectos luminosos; en los segundos las materializaciones fluídicas de pies o manos; y en los últimos, los falsos, las materializaciones corpóreas -como Leonor- y «muy especialmente la mediumnidad en su sentido verdadero, esto es, como acción intermediaria entre los desencarnados y los vivientes» (Comas, 1908, p. 76).

En las sesiones espiritistas, la prueba de la materialización fluídica de un miembro solía obtenerse mediante la impresión de su huella en un molde de cera o sobre papel ahumado. Este tipo de evidencia fue la que sirvió a Comas y Fornaguera para discutir sobre el desdoblamiento corporal en la médium Carmen; pero antes de analizar el caso, veamos cómo entiende Comas el desdoblamiento en sentido físico:

La transe significaría, por consiguiente, el alejamiento de un elemento del cuerpo del individuo, la separación de uno de los individuos elementales invisibles e imponderables, si es que existen varios de este orden.

En fin, el nuevo individuo imponderable e invisible, alejado total o parcialmente del médium, llevaría las mismas fuerzas y la misma mentalidad del médium pero necesariamente aminoradas (como aminoradas quedan las facultades del médium en transe) y sus superficies de contorno (forma) serían iguales a las del médium; obrarían sobre la fuerza ponderable y produciría fenómenos físicos más o menos intelectualizados (Comas, 1908, p. 88).

Este «individuo invisible» que se desdobla del médium es otra forma de llamar al doble de las ya nom- 
bradas. Para Comas, el doble «representa el cuerpo invisible de este segundo yo" (Comas, 1908, p. 79). Se trataba, como opinaba Melcior (1904), de un desdoblamiento de la personalidad llevado a su grado máximo. Como se expone en la cita, para Comas (1908) el origen de los fenómenos intelectualizados -como la escritura automática- se explicaba porque el doble poseía la misma mentalidad del médium, aunque aminorada. Melcior opinaba de manera similar, pues creía que «a la exteriorización de la fuerza psíquica le acompaña tácitamente la inteligencia» (Melcior, 1904, p. 320)

Como Teresa Esquius no formaba parte de ningún grupo espiritista convencerla de que Teresina era una creación de su inconsciente no fue complicado, pues ante todo quería deshacerse de los fenómenos que producía sin control (Melcior, 1904). Más difícil era el caso de Carmen. Al estar vinculada a los círculos espiritistas no le convenía plantear que Leonor era producto de un desdoblamiento. Sin embargo, Comas no dudó en concluir que «ninguno de los fenómenos físicos e intelectuales producidos [por Carmen] revela la acción de otro ser distinto de la médium» (Comas, 1908, p. 76). La prueba que aportó para sostener su afirmación fue la huella de un pie, supuestamente de Leonor, impresa sobre papel ahumado. Curiosamente, el médium y espiritista Jacint Fornaguera (1908a, 1908b) había usado antes esta misma prueba para afirmar lo contrario.

La huella del pie se había obtenido durante una de las sesiones de 1907. Fornaguera (1908b) destacó las condiciones inmejorables y poco frecuentes en las que se llevó a cabo. En esa ocasión había «la suficiente luz para distinguirla [a Carmen] en todo momento" (Fornaguera, 1908b, p. 21). Los asistentes y la médium se reunieron en torno a una mesa con las manos sobre ella, como en los inicios del espiritismo con las mesas giratorias y parlantes (Véase: González de Pablo, 2006a). El papel ahumado se hallaba en un cajón dentro del gabinete oscuro, situado detrás de la médium, a quien también sujetaron los pies (Fornaguera, 1908b).

La huella del pie fue presentada como una prueba irrefutable de la existencia de Leonor en la publicación espiritista Los Albores de la Verdad. Para argumentar que pertenecía al espíritu de Leonor y no al pie de la médium, Fornaguera aludió a determinadas diferencias físicas. La más significativa era que "la huella dejada por el pie de Leonor (espíritu) es cerca dos centímetros más corta que la del pie de la médium» (Fornaguera, 1908b, p. 21).

Lo primero que hizo Comas al hallar la huella fue pedir permiso a de Sard, director de las sesiones, para compararla con el pie de la médium. La única diferencia que advirtió fue la que aludió Fornaguera respecto a la longitud de la planta, discrepancia que, según Comas, «era perfectamente explicable por la variación de presión del pie sobre el papel ahumado» (Comas, 1908, p. 113). Del mismo modo opinó el médico Pedro Farreras (1908), quien remitió una carta a Comas con sus notas comparativas entre el pie de Carmen y la huella obtenida en la sesión.

Comas no tachó el fenómeno de fraudulento, pues no era capaz de explicarse la superchería, pero tampoco aceptó la explicación espiritista de Fornaguera. En su opinión, el fenómeno coincidía con la teoría del desdoblamiento tal y como se ha visto que él la entiende. De este modo, concluyó Comas, «si el fenómeno fuese legítimo, constituiría una brillante confirmación de mi hipótesis de la mediumnidad, pues, según ella, todas las huellas o imágenes plásticas de miembros fluídicos e invisibles deben ser una reproducción exacta de los de la médium» (Comas, 1908, p. 114) -en cuanto son producto del «individuo invisible» desdoblado.

Esta no era la primera vez que la coincidencia de las huellas del médium con las del supuesto espíritu se interpretaba como una prueba a favor del desdoblamiento. En las sesiones de Roma (1893-1894) con Eusapia Palladino, bajo la dirección de Siemiradski y Ochorowicz, se llegó a la misma conclusión al ver que la huella de la mano del supuesto espíritu coincidía con la de la médium (Gota, 1909b). Esta clase de pruebas materiales fueron de suma importancia para traducir los fenómenos observados en hechos concretos a favor de una determinada hipótesis. Para algunos espiritistas, las imágenes de ectoplasmas emanados por el médium representaban una prueba irrefutable de su existencia (Brower, 2010; Edelman, 2006a). Asimismo, la fotografía donde Florence Cook aparece al lado del fantasma de Katie King fue presentada por Crookes como una prueba de la materialización de dicho espíritu (Brock, 2008).

Fornaguera no estaba dispuesto a aceptar la teoría del desdoblamiento, ni el caso de Carmen ni en sentido general. Según él, el problema de las sesiones con Carmen fue que Comas se había negado a acatar las condiciones requeridas. Uno de los principios básicos para el estudio de los fenómenos del espiritismo era que los observadores tenían que mostrarse benevolentes y confiados, de no ser así se "empujaba» al médium a cometer un fraude (Blondel, 2002). A este hecho se refiere Fornaguera al apuntar:

¿Qué opina el Sr. Comas y Solá de estas acciones inteligentes sobre objetos, si niega la acción de los desencarnados con los vivos?. Quizás supone que el médium, desdoblándose, puede hacerlo? $Y$ aunque así fuera, no serían precisas, para ello, ciertas condiciones (negadas por el Sr. Comas, que si no las niega por lo menos dice ignorar el por qué) de afinidad, armonía, etc.? (Fornaguera, 1908b, p. 20). 
Tras criticar los controles exigidos por Comas, Fornaguera rebatió la teoría del desdoblamiento del médium de la manera siguiente:

Y si la inteligencia del médium pudiera manifestarse fuera del mismo, no demostraría esto que la inteligencia (espíritu) fuera del cuerpo se relaciona con los vivos? Y un médium, si quisiera voluntariamente hacerlo, necesitaría tener un conocimiento grande de los elementos etéreos (invisibles) para manejarlos a su antojo.

Bien sabe el Sr. Comas y Solá que los médiums por él estudiados no poseen este conocimiento tan indispensable en el caso que nos ocupa. (Fornaguera, 1908b, p. 20).

Los argumentos de Fornaguera se resumen en uno: los fenómenos del espiritismo solo puede producirlos un ser inteligente, pero este no puede ser el médium, pues desconoce cómo lograr que su inteligencia se manifieste fuera de su cuerpo. Entonces, se debe suponer que esta inteligencia es la de un espíritu. Se observa aquí el principal punto de confrontación entre la teoría espiritista y la del desdoblamiento que, sin negar los fenómenos mediúmnicos, refuta la hipótesis espírita (Boirac, 1910). Comas lo dejó claro al dar por falsa la mediumnidad en su sentido espiritista, es decir, como agente mediador con los desencarnados: "la mediumnidad, si es que existe, es un fenómeno natural como cualquier otro, $y$, como todos, sujeta a la misma ley o escala de probabilidades o de frecuencias, o mejor, de continuidad" (Comas, 1908, p. 124). Esta opinión no difería de la Morselli (1908) o Richet (1923); sin embargo, las leyes que gobernaban la mediumnidad eran difícilmente deducibles, ya que sus fenómenos eran espontáneos y ni siquiera se conocían la mayoría de condiciones favorables para su producción (Blondel, 2002).

Tras las polémicas sesiones con Carmen, Comas se ofreció a experimentar en su casa con el médium que se presentase voluntario. La única condición que impuso fue que las sesiones se hicieran, en palabras de Comas: «bajo mi sola autoridad y procediendo con todo el rigorismo y valiéndome de todos los controls que se me ocurran (inofensivos por supuesto)» (Comas, 1907, sin numeración). De no hallar fraude alguno, Comas prometió hacerlo público «en bien de la Ciencia y para honra del médium» (Comas, 1907, sin numeración).

Según Fornaguera (1908a), el ofrecimiento de Comas era consecuencia de una conversación, supuestamente airada, que habían mantenido en la redacción de La Actualidad. Visiblemente molesto, el médium y presidente del centro "Amor Universal» adujo:

¿Cómo quiere el Sr. Comas que nos prestemos los verdaderos médiums a ser examinados bajo su dirección si él ha demostrado no poseer lo que se requiere para di- rigir aquello que demuestra desconocer?, opina tal vez que nosotros seremos tan mentecatos de ir a su casa para ello?, lo cree natural? (Fornaguera, 1908a, p. 60).

Como predijo Fornaguera, pasados tres meses ningún médium se ofreció voluntario (Comas, 1908).

\section{APUNTE FINAL: HACIA UN ESTUDIO CIENTÍFICO DE LA MEDIUMNIDAD}

La mediumnidad definida mediante términos como el desdoblamiento de la personalidad o la exteriorización del doble era muy distinta de la defendida por los espiritistas. Quienes la entendieran del primer modo, como Melcior o Comas, difícilmente podrían estudiarla dentro de un grupo espiritista que únicamente abogara por la comunicación espiritual. Como opinaban Antonio Gota (1910) y Emile Boirac (1910), el científico que quisiera emprender el estudio imparcial del espiritismo debía basarse únicamente en su fenomenología. En este sentido, existía la creencia positivista de que estos fenómenos podían ser estudiados de forma neutral y empírica. Comas así lo habría intentado si algún médium, después de Carmen Domínguez, se hubiera prestado voluntario.

Como Schrenck-Notzing, Comas (1908) y Estrany (1908) opinaban que los médiums no estaban entrenados en la experimentación científica sino en las sesiones espiritistas, por lo que tenían que ser «reeducados». En el laboratorio parapsicológico de Schrenck-Notzing médiums como Schneider tuvieron que acostumbrase a obrar controlados por aparatos que registraban su pulso o sus movimientos (Wolffram, 2009a, 2009b). En este sentido, el médium pasó a estar sometido al investigador, a diferencia de lo que ocurría en las sesiones espiritistas, donde gobernaba la sesión.

La indignación de Fornaguera respecto a los controles exigidos por Comas es comprensible. ¿Por qué iba un "verdadero» médium a ceder ante Comas si, según Fornaguera, ni siquiera era un "experto» en la materia? Además, si la mediumnidad, en el sentido de la comunicación espiritual, representaba parte del sustento del médium -como en el caso de Carmen-, ¿para qué someterse a unas experiencias que partían de hipótesis contrarias a la espírita? Incluso, si tras experimentar con Comas u otros, no se descubría fraude alguno, ¿acaso los espiritistas, sus principales "clientes», se interesarían por un médium en cuyos fenómenos no intervinieran los espíritus? Estos son solo algunos de los motivos que llevaron a médiums espiritistas, como Jacint Fonraguera o Segundo Oliver, a enfrentarse a las teorías del desdoblamiento en pro de la "verdadera» mediumnidad.

Es posible que si Comas hubiera ofrecido una retribución económica algún médium hubiera aceptado so- 
meterse a sus controles. No hay que olvidar que, entre otros, Eva $C$. fue pagada por sus sesiones con Piéron en la Sorbonne (Lachapelle, 2011). El peligro de la retribución era el mismo que conllevaba experimentar con médiums públicos: aumentaba la posibilidad del fraude. De no hallar superchería alguna, la promesa de Comas fue hacerlo público «en bien de la Ciencia y para honra del médium» (Comas, 1907, sin numeración). Pero, de nuevo, ¿de qué clase de honra se trataba?, ¿̇la de sufrir un desdoblamiento de la personalidad que, mediante la irradiación de una fuerza desconocida, producía fenómenos propios del espiritismo? Si se aceptaba la teoría del desdoblamiento en el sentido psicopatológico de Janet la conclusión lógica era «curar» al médium, como hizo Melcior con Teresa Esquius. Planteado de esta manera, más "honroso» le podía parecer a un médium creerse posesor de una facultad que le permitiera comunicarse con los espíritus.

Para médicos como Melcior, interesado en estudiar la mediumnidad mediante las teorías del desdobla- miento, la hipótesis espírita solo había conseguido ahuyentar la comunidad científica. En su opinión, si desde el inicio el caso de Teresa Esquius se hubiera asociado con el desdoblamiento, en vez de con el espiritismo, más hombres de ciencia se habrían interesado por el origen de los fenómenos. En este sentido, para Melcior las teorías del desdoblamiento fueron una herramienta para desvincular la mediumnidad de su pilar espiritista.

Al definir la mediumnidad de Carmen y Teresa mediante el desdoblamiento, ya fuera físico o mental, Comas y Melcior contribuyeron a que ésta se estudiara científicamente. Usando la expresión de Ochorowicz (en: Rochas, 1897, p. 130), fueron «mediumnistas» antes que espiritistas. De este modo, se situaron en la línea de contemporáneos como Morselli (1908) o Richet (1923). Como ellos, buscaron alejarse de la hipótesis espírita y repensar la mediumnidad mediante explicaciones físicas y psicológicas, especialmente vinculadas a la noción del inconsciente.

\section{NOTAS}

1 Richet define la metapsíquica como "una ciencia que tiene por objeto de estudio la producción de fenómenos, mecánicos o psicológicos, debidos a fuerzas que parecen inteligentes, o poderes desconocidos, latentes en la inteligencia humana». Richet, (1923), p. 4, la cursiva es del original. En este artículo usaré la versión traducida de la obra.

2 Así describe Lombroso a Leonor: «En Barcelona, Marata, con la médium Carmen Domínguez, en la cuarta sesión se le apareció

Leonor, fantasma completamente materializado que saludó a los presentes con voz un poco velada. Desapareció a los pocos minutos, volvió a entrar y salir muchas veces de la cámara y una vez permaneció entre los espectadores casi una hora, revelando una inteligencia poco común. Se sentó tres o cuatro veces en una silla que trajo de la cámara mediúmnica, dio la mano a los presentes, permitió que le tocaran su negra cabellera y su blanca vestimenta, que pareció a todos de finísimo tul con reflejos luminosos». Lombroso (1993), p. 235

\section{BIBLIOGRAFÍA}

Abend, Lisa (2004), "Specters of the Secular: Spiritism in Nineteenthcentury Spain", European History Quarterly, (4), pp. 507-534.

Alvarado, Carlos S. (2002), "Dissociation in Britain during the late nineteenth century: the Society for the Psychical Research, 18821900", Journal of Trauma and Dissociation, (2), pp. 9-33.

Alvarado, Carlos S. (2006),"Human radiations: Concepts of force in mesmerism, spiritualism and psychical research", Journal of the Society for Psychical Research, (884), pp. 138-162.

Alvarado, Carlos S. (2010), “'Divisions of personality and spiritism' by Alfred Binet (1896)", History of Psychiatry, pp. 487-500.

Anónimo (1895), "Clínia hidro-magnética”, Revista de Estudios Psicológicos, 24, p. 145.

Bacopoulos-Viau, Alexandra (2012),"Automatism, Surrealism and the making of French psychopathology: the case of Pierre Janet", History of Psychiatry, (3), pp. 257-276.

Bensaude-Vincent, Bernadette; Blondel, Christine (2002), Des Savants face à l'occulte 1870-1940, Paris, Éditions La Découverte.

Binet, Alfred (1892), Les Altérations de la personnalité, Paris, Félix Alcan.

Blondel, Christine (2002), «Eusapia palladino: La méthode expérimentale et la 'diva des savants'», En: Bensaude-Vicent, Bernadette; Blondel, Christtine (Eds.), Des savants face à l'occulte 1870-1940 (pp. 143-171). Paris, Éditions La Découverte. 
Boirac, Emile (1910), "L'etude scientifique du spiritisme», En: Durville, Henri, (Ed.), Congrès international de psychologie expérimentale: Réuni à paris, du 15 au 20 novembre 1910: Compterendu des travaux, Paris: Henri Durville fils, pp. 118-134.

Brock, William H. (2008), William Crookes (1832-1919) and the commercialization of science. Ashgate, Aldershot.

Brower, M. Brady (2010), Unruly spirits:the science of psychic phenomena in modern France, Urbana, University of Illinois Press.

Cembrano, José (1908), "El Espiritismo y el Sr. Comas Solá", La Voz De La Verdad, (1), pp. 1-2.

Comas y Solà, Josep (1907), "El espiritismo ante la ciencia. Juicio crítico sobre la mediumnidad. Epílogo", La Actualidad, (73).

Comas y Solà, Josep (1908), El Espiritismo ante la ciencia, Barcelona, F. Granada.

Comisión de organización de la Sección Espiritista (1900), “Congreso espiritista y espiritualista”, Luz y Unión, (9), pp. 84-85.

Crabtree, Adam (1993), From Mesmer to Freud: magnetic sleep and the roots of psychological healing, New Haven etc., Yale University Press.

Delanne, Gabriel (1900),"Congreso espiritista y espiritualista de 1900", Luz y Unión, (11), pp. 105-107.

Durville, Hector (1909), "El fantasma de los vivos", Lo Maravilloso, 1(5), pp. 49-52.

Edelman, Nicole (2003), Les Métamorphoses de l'hystérique, Paris, La Découverte.

Edelman, Nicole (2006a), Histoire de la voyance et du paranormal, Paris, Seuil.

Edelman, Nicole (2006b), "Lo oculto y las terapéuticas espiritistas del espíritu y del cuerpo en Francia (1850-1914): de la creencia al saber y vuelta", Asclepio, (2), pp. 39-62.

Ellenberger, Henri F. (1976), El Descubrimiento del inconsciente, Madrid, Gredos.

Esteva Marata, Jacinto (1908),"El caso del Sr. Comas Solá", La Voz De La Verdad, (1), pp. 3.

Estrany, Jeroni (1908),"Carta abierta". En: Comas i Solà, Josep. El espiritismo ante la ciencia, Barcelona, F. Granada, pp. 127-147

Farreras, Pedro (1908). “Carta”. En: Comas i Solà, Josep. El espiritismo ante la ciencia, Barcelona, F. Granada, pp. 114-115.

Fornaguera, Jacint (1908a), El Espiritismo ante la ciencia: sobre un juicio crítico publicado por D. J. Comas Solá, Barcelona-San Martín, Tip. "La Moderna".

Fornaguera, Jacint (1908b),"El espiritismo ante la ciencia. Sobre un juicio crítico publicado por el Sr. Comas y Solá en la revista 'La Actualidad'", Orbi...!, (67), pp. 19-21.

Franco, John Joseph (1890), El Hipnotismo clarovidente, ó, Pickman y Lombroso en Turín (J. Font i de Boter Trad.), Barcelona, Imp. y Librería de la Inmaculada Concepción.
García Gonzalo, Eugenio (1897), "La psicofísica y el espiritismo", Revista De Estudios Psicológicos, pp. 296-298.

González de Pablo, Ángel (2003), “El hipnotismo en la españa del primer tercio del siglo XX”, En: Montiel, Luis; González de Pablo, Ángel (eds.), En ningún lugar, en parte alguna: Estudios sobre la historia del magnetismo animal y del hipnotismo. Madrid: Frenia, pp. 229-299.

González de Pablo, Ángel (2006a), "Sobre los inicios del espiritismo en España: La epidemia psíquica de las mesas giratorias de 1853 en la prensa médica", Asclepio, (2), pp. 63-69.

González de Pablo, Ángel (2006b), "Animal magnetism in Spanish medicine (1786-1860)", History of Psychiatry, (3), pp. 279-298.

Gota Casas, Antonio (1909a), "La ciencia y los fenómenos espiríticos contemporáneos", La España Moderna, (247), pp. 143-159.

Gota Casas, Antonio (1909b), "La ciencia y los fenómenos espiríticos contemporáneos", La España Moderna, (248), pp. 82-103.

Gota Casas, Antonio (1910), “¿Debe estudiarse el espiritismo?”, La España Moderna, (254), pp. 55-83.

Gota Casas, Antonio (1911a), "El Renacimiento de la Antigua Magia”, La España Moderna, (266), pp. 47-75.

Gota Casas, Antonio (1911b), "El Renacimiento de la Antigua Magia”, La España Moderna, (267), pp. 35-55.

Horta, Gerard (2001), De la mística a les barricades, Barcelona, Proa.

Horta, Gerard (2004), Cos i revolució. L'espiritisme català o les paradoxes de la modernitat, Barcelona, Edicions de 1984.

Janet, Pierre (1889), L'Automatisme psychologique: essai de psychologie expérimentale sur les formes inférieures de l'activité humaine (4a ed. 1898), Paris, Félix Alcan.

Kardec, Allan (2009), El libro de los médiums, Málaga, Sirio.

Lachapelle, Sofie (2005), "Attempting science: The creation and early development of the Institut Métapsychique International in Paris, 1919-1931", Journal of the History of the Behavioral Sciences, (1), pp. 1-24.

Lachapelle, Sofie (2011), Investigating the supernatural:from spiritism and occultism to psychical research and metapsychics in France, 1853-1931, Baltimore, Johns Hopkins University Press.

LéBlanc, André (2001), "The origin of the concept of dissociation: Paul Janet, his nephew Pierre, and the problem of post-hypnotic suggestion", History of Science, pp. 57-67.

Lombroso, Cesare (1993), Los fenómenos de hipnotismo y espiritismo, Barcelona, Editora Amelia Boudet.

López Gómez, Quintín (s.d. 1919?), Filosofia (3ạ, cuidadosamente revisada y aumentada ed.), Barcelona, Maucci.

Méheust, Bertrand (1999), Somnambulisme et médiumnité, vol. 2: Le choc des sciences psychiques, Paris, Synthélabo. 
Melcior i Farré, Víctor (1895), “Notas clínicas del consultorio médico hidro-magnético", Revista De Estudios Psicológicos, pp. 125-127.

Melcior y Farré, Víctor (1900), La enfermedad de los místicos (patología-psíquica), Barcelona, Establecimiento Tipográfico de Juan Torrents y Coral.

Melcior y Farré, Víctor (1904), Los Estados subconscientes y las aberraciones de la personalidad, Barcelona, Carbonell y Esteva.

Morselli, Enrico (1908), Psicologia e "spiritismo", Torino, Milano, Roma, Fratelli bocca.

Montiel, Luis; González de Pablo, Ángel, (2003), En ningún lugar, en parte alguna:estudios sobre la historia del magnetismo animal y del hipnotismo, Madrid, Frenia.

Mülberger, Annette (2008), "Marginalisation de la parapsychologie et du spiritisme dans le discorus scientifique en Espagne», L'Homme Et La Societé, (167/168/169), pp. 101-118.

Mülberger, Annette; Balltondre, Mònica, (2012), "Metapsychics in Spain: Acknowledging or questioning the marvellous?", History of the Human Sciences, (2), pp. 108-130.

Mülberger, Annette; Balltondre, Mònica, (2013), "En el umbral de lo desconocido: Un caso de visión extraordinaria en la España de Primo de Rivera", Dynamis 33(1), pp. 195-216

Myers, F. W. H. (1903), Human personality and its survival of bodily death, London, Longmans, Green.

Ochorowicz, Julian (1887), De la suggestion mentale, Paris, O. Doin.

Oliver, Segundo (1901), "Clericales y sectarios de Roma, materialistas y neantistas, impugnadores del espiritismo", Luz y Unión, (49), pp. 393-394.

Oppenheim, Janet (1985), The Other world: spiritualism and psychical research in England, 1850-1914, Cambridge etc., Cambridge University Press.

Owen, Alex (2004), The place of enchantment: British occultism and the culture of the modern, Chicago, IL, University of Chicago Press.

Plas, Régine (2000), Naissance d'una science humaine: la Psychologie. Les psychologues et le 'merveilleux psychique', Rennes, Presses Universitaires de Rennes.

Plas, Régine (2012), "Psychology and psychical research in France around the end of the 19th century", History of the Human Sciences, (2), pp. 91-107.
Primer Congreso Internacional Espiritista: Septiembre 1888 Barcelona: Representaciones, adhesiones, sesiones públicas... (1888), (Ed. española), Barcelona, Imprenta de Daniel Cortezo y Ca.

Richet, Charles (1923), Tratado de metapsíquica. Prólogo de Jaume Ferran. Barcelona, Araluce.

Roca, Antonio (1986), "Los ecos de un debate internacional". En: Comas i Solà, Josep (Ed.), El espiritismo ante la ciencia, Barcelona: Alta fulla, pp. V-XXVII.

Rochas d'Aiglun, Albert de (1897), Exteriorización de la motilidad (V. Melcior i Farré Trad.), Barcelona, Impr. de Pujol y Ca.

Sánchez Herrero, Abdón (1897), "Prólogo”. En: Rochas d’Aiglun, Albert de (Ed.), Exteriorización de la motilidad, Barcelona: Impr. de Pujol y Ca, pp. VII-XVI.

Sard, Antonio de (1908), “Comentarios a los artículos del señor Comas Solá sobre la Mediumnidad", La Voz De La Verdad, (1), p. 2.

Shamdasani, Sonu (1993), "Automatic writing and the discovery of the unconscious", Spring 54, pp. 100-131.

Shamdasani, Sonu (1994), "Encountering Hèlene. Théodore Flournoy and the genesis of subliminal psychology". En: Flournoy, Théodore, From india to the planet mars: A case of multiple personality with imaginary languages, Princeton N.J.: Princeton University Press, pp. XI-LI.

Sommer, Andreas (2011), "Professional heresy: Edmund Gurney (1847-88) and the study of hallucinations and hypnotism", Medical History, (55), pp. 383-388,

Tolosa Latour, Manuel (1884), Las Fuerzas físicas y la fuerza psíquica:memoria leída el 7 de noviembre de 1884 en el Ateneo de Madrid, Madrid, Gutenberg.

Valentí Camp, Santiago; Massaguer, Enrique, (1912), Las Sectas y las sociedades secretas a través de la historia, Barcelona, Antonio Virgili.

Wolffram, Heather (2009a), The Stepchildren of Science. Psychical Research and Parapsychology in Germany, c.1870-1939, Amsterdam, New York, Rodopi.

Wolffram, Heather (2009b), "In the laboratory of the Ghost-Baron: parapsychology in Germany in the early 20th century", Endeavour, (4), pp. 152-157.

Wolffram, Heather (2012), “'An object of vulgar curiosity': legitimizing medical hypnosis in imperial Germany", Journal of the History of Medicine and Allied Sciences, (1), pp. 149-176. 